\title{
What is a CLIP note?
}

\author{
By the CIS CLIP Notes Committee \\ P. Grady Morein, Chair
}

\section{ACRL's College Libraries Section is generating a valuable series of reports on current library practices.}

$\mathrm{C}$ LIP Notes is a program of the Association of College and Research Libraries. The title is derived from the concept, College Library Information Packet Notes. Initiated in 1980 by the Continuing Education Committee of ACRL's College Libraries Section, the program provides college and small university libraries with state-of-the-art reviews and current documentation on library practices and procedures of relevance to them.

The function of the CLIP Notes program is to share information among smaller academic libraries as a means of facilitating decision making and improving performance. The basic premise underlying the program is that libraries throughout the nation are facing numerous challenges due to changing environments and that many of these libraries can benefit by knowing how similar institutions have resolved certain problems.

A CLIP Note is a publication containing a stateof-the-art report on a current library practice and a collection of documents related to that practice. Documents consist of policy statements, procedure descriptions, reporting forms and the like. Information for a CLIP Note is generally gathered through surveys of colleges and small universities and reviews of the literature.

The process for creating a CLIP Note has evolved over time. Initially the CLS Continuing Education Committee performed all of the tasks required in constructing a CLIP Note. Also various approaches and survey groups were used in collecting data and documents. Three CLIP Notes were produced using these procedures.

Following production of the third CLIP Note, the Continuing Education Committee realized that future CLIP Notes could be more efficiently produced by an editorial committee responsible for operating and expanding the program. Thus a committee was formed and charged to develop processes for operating a permanent CLIP Notes program.

The task considered of prime importance by the committee was the establishment of a stable survey group that would respond to questionnaires and would also be willing to share documents with other libraries. The group also had to be representative of college and small university libraries as a whole and willing to participate in survey programs on a continuing basis.

A second major concern of the committee was to develop procedures for constructing the CLIP Notes program that would provide all interested librarians the opportunity to create CLIP Notes.

Focusing on the first of these issues, the committee examined several groupings of libraries or colleges that were considered most representative and stable. The pool ultimately selected is composed of two groups from the Carnegie Council on Policy Studies in Higher Education. These are: 1) Comprehensive Universities and Colleges I, and 2) Liberal Arts Colleges I. All libraries from these two groups with a minimum enrollment of 1,000 and a maximum enrollment of 5,000 as reported in the 1976 Carnegie list were sent a questionnaire which asked, among other things, whether they would be willing to respond to future CLIP Note surveys. Approximately 200 libraries agreed to participate on a continuing basis. 


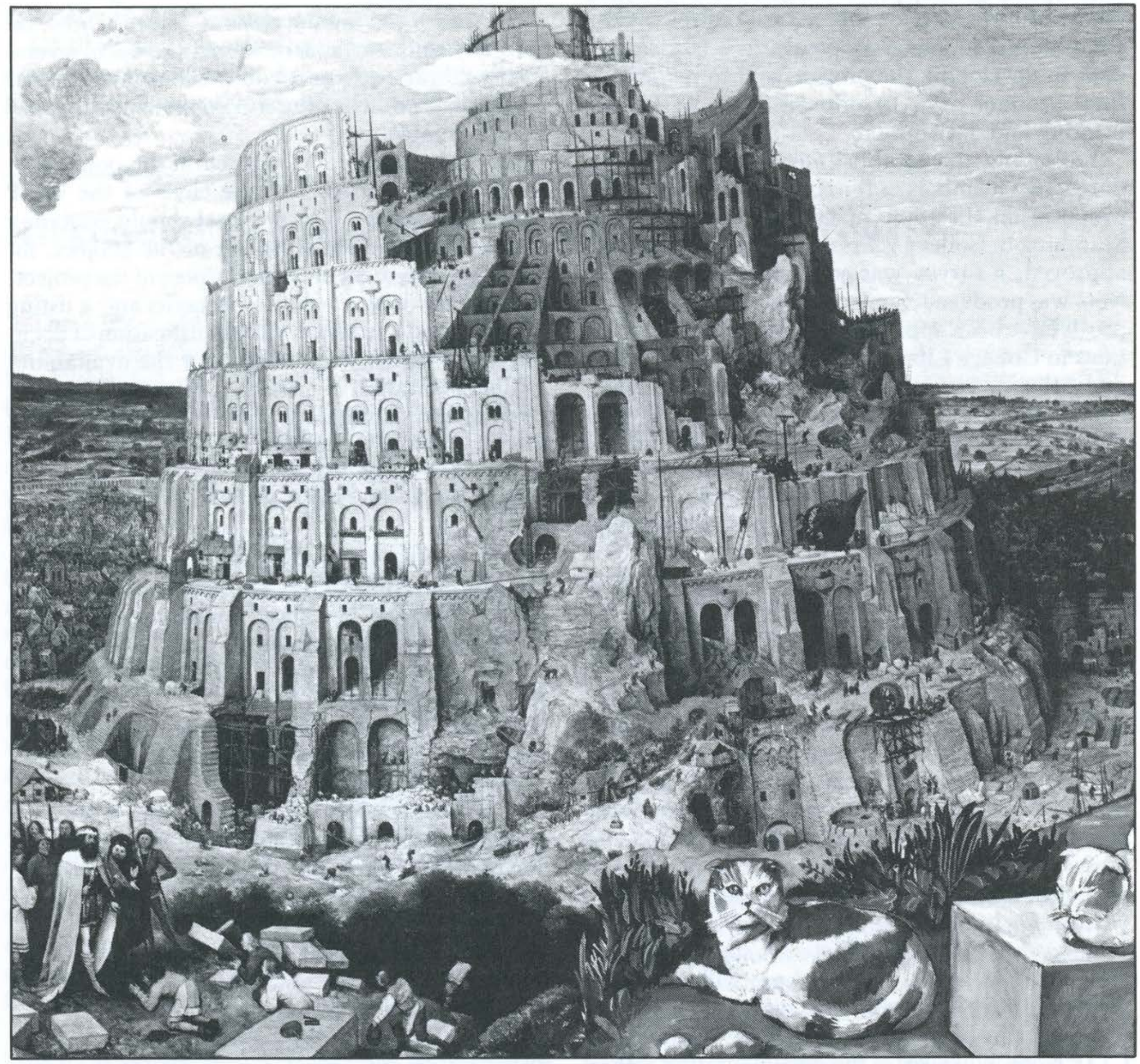

\section{Do you and your book wholesaler speak the same language?}

Sometimes it takes one well-trained and skilled librarian to fully understand the real needs of another.

That's why Baker \& Taylor has made a point of having more trained librarians on staff than any other book supplier.

These professional librarians are dedicated to helping you get the most benefit from Baker \& Taylor's specialized services.

So when you order from Baker \& Taylor you can be assured that nothing will ever get lost in the translation.

Call or write us now BAKER \& TAYLOR for more information. 
In addressing the second issue, that of providing the means whereby librarians would be encouraged to propose and develop a CLIP Note, the committee created a system wherein interested participants develop projects under the direction of the committee. Under this system the role of the committee is to screen proposals, to provide guidance in developing the project, and to review the final product prior to submission to ACRL for printing and distribution.

Following the establishment of these procedures, two members of the committee submitted a proposal on the topic of "Online Bibliographic Searching in College Libraries." The proposal was approved, a survey was conducted, and a CLIP Note was produced. Since then two additional proposals have been approved: one on "Special Collections in College Libraries," and another on "Goal and Mission Statements for College Libraries." Surveys on these two issues are now being conducted and CLIP Notes will be available within the year. Thus, the two major goals of the committee have been achieved: a survey group has been established, and procedures have been instituted for developing the program.

The challenge now faced by the committee is to generate greater participation in the program. While the task of developing a CLIP Note is complex, the need for good documentation on timely issues is significant. Thus there is considerable opportunity for anyone interested in developing a CLIP Note. There is no shortage of topics. Any subject of interest to college and small university libraries is a potential topic. The principal requirement for success is the availability of documents useful to other libraries. New approaches to service, different ways of organizing operations, procedures for handling new technology-all are excellent subjects for CLIP Notes. A state-of-the-art assessment of issues such as these will generally yield significant information as well as useful documents worthy of publication. The key feature of a CLIP Note, however, is the documentation rather than the assessment. Thus the best situation for developing a CLIP Note is one in which there is a strong need for current information on practices, procedures or policies, and the availability of a number of high quality documents which can be shared with other libraries.

Considerable time and effort have been focused on developing a structure for operating the CLIP Note program. That structure is in place and functioning. The need now is for wider involvement in order to generate increased numbers of useful products.

Anyone interested in developing a CLIP Note is urged to submit ideas following the procedures listed below:

1. Send an "intent to submit a proposal" to any member of the CLIP Notes Committee. This should be a one or two page description of a basic idea that you think would make a good CLIP Note.
2. The committee member receiving this description will respond to the idea, suggesting how to develop the topic or recommending changes. If deemed necessary other members of the committee will be consulted.

3. After receiving the response, test the idea informally among friends or acquaintances in several college libraries. In particular, determine whether a sufficient number of useful documents are likely to be available.

4. If the project appears viable at this point, submit a formal proposal to the chair of the CLIP Notes Committee. The proposal should contain a two or three page description of the project, including a statement of need, purpose of the project, anticipated results, expected benefits and a listing of potential documents. The identification of documents is especially important, for the availability of documentation is critical to success. The proposal should also contain a well-developed draft of the questionnaire that is to be sent to the survey group. The final component of the proposal is a budget for conducting the survey and collecting the documents. Allowable expenditures include the cost of copying the questionnaire, postage for mailing original and follow-up questionnaire, basic supplies, limited computer processing, and possibly telephone. The committee supplies address labels for the survey group. The cost of previous surveys has been less than $\$ 200$.

5 . The committee chair will circulate the proposal among committee members for their review, response and approval.

6. Once approved, proceed to develop the final questionnaire, conduct the survey, and collect the documents. The entire committee will provide guidance and assistance throughout this stage of the project.

7. Upon completion of the survey analyze the results, select the documents to be included in the final product, then organize the material and write a report. The report will consist of an analysis of survey results and a brief introduction to the documents. Generally the analysis is limited to five or six pages. The number of documents to be included is variable. Usually, however, these should be highly selective and limited in number. Existing CLIP Notes may be reviewed for examples.

8. At this point the product is circulated to the committee for final review and suggestions for refinement.

9. Finally the material is sent to ACRL for printing. ACRL can produce the report on a highquality word processor and has the ability to reduce documents prior to printing.

CLIP Notes is one of the most useful of ACRL's college library programs. It focuses directly on the needs of college and small university libraries, providing concrete tools for addressing specific problems and concerns. Currently, CLIP Notes are available on Performance Appraisal, Collection Development, Job Description, and Online 
Searching. The policies, procedures, and operating guidelines contained in these publications provide a wealth of information for college and small university libraries. If you would like to participate in developing a CLIP Note, please send your ideas to any of the committee members listed below.

CLIP Notes Committee members: P. Grady Morein (chair), University Librarian, University of Evansville, Evansville, IN 47702; David Carlson,
Library Systems Analyst, University of Rhode Island, Kingston, RI 02881; Nancy Coxe, Reference Librarian, George Washington University, Washington, DC 20008; Larry Hardesty, Library Director, Eckerd College, St. Petersburg, FL 33733; Kenneth Oberembt, Library Media Resources Director, University of Scranton, Scranton, PA 18510.

\section{Kirkendall honored as BI Librarian of the Year}

The winner of the 1985 Miriam Dudley Bibliographic Instruction Librarian of the Year is Carolyn Kirkendall, director of the LOEX Clearinghouse at Eastern Michigan University since 1975. Kirkendall will be presented with the award at the ACRL Bibliographic Instruction Section's program meeting on Tuesday, July 9, 2:00-5:30 p.m., in Chicago.

Kirkendall's contributions have had a truly national impact and have been sustained over a period of many years. As LOEX director, she has a major role in planning the annual LOEX Conference on Library Orientation for Academic Libraries. She has presented papers at the Conference regularly and has edited a number of volumes of the proceedings for Pierian Press, including Putting Library Instruction in Its Place (1977) and Directions for the Decade (1980). She has edited the LOEX News since 1976 and "Library Instruction: A Column of Opinion" in the Journal of Academic Librarianship from 1976 to 1982 . She coordinated the ACRL BI Liaison Project for several years, promoting bibliographic instruction in professional associations within and outside of the library and information science fields.

The Miriam Dudley Award consists of $\$ 1,000$ presented to a librarian who has made an especially significant contribution to the advancement of bibliographic instruction. It honors Miriam Dudley, reference librarian at the University of California, Los Angeles, whose pioneering efforts in the field of bibliographic instruction led to the formation of the Bibliographic Instruction Section. The award has been funded by Research Strategies, Ann Arbor, Michigan.

Nominees should have achieved distinction in such areas as planning and implementation of a bibliographic instruction program that has served

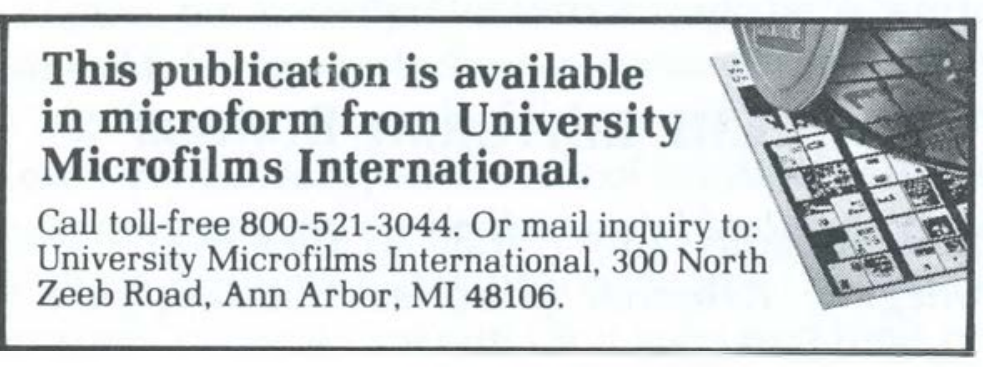

as a model for other programs; development of courses on bibliographic instruction in ALAaccredited library schools, or development of BI continuing education courses that have served as models for other courses; research and publication that has had a demonstrable impact on the concepts and methods of teaching bibliography; and active participation in organizations devoted to the promotion and enhancement of bibliographic instruction.

The deadline for nominations in letter form for the 1986 award is December 1, 1985. Send nominations to William Miller, Jerome Library, Bowling Green State University, Bowling Green, $\mathrm{OH}$ 43403.

\section{Now there's help}

The ACRL Professional Association Liaison Conmittec was created to promote cooperative efforts with other higher education associations. The Committee is to carry on the work of the Bibliographic Instruction Liaison Project on a broader scale, helping librarians participate in the programs of other associations. As an example, Mary George of Princeton University is chairing a panel for the meeting of the National Council of Teachers of English next fall in Philadelphia.

There are funds in the ACRL budget for this fiscal year (ending August 31, 1985) to support registration fees and partial travel for librarians who will give papers on library-related topics (online searching, BI, etc.) at the meetings of non-library professional associations.

Librarians who wish to apply for support to attend meetings at which they will give a paper, be on a panel, etc., can apply for partial support to the chair of the Professional Association Liaison Committee, Joan Chambers, University Librarian, University of CaliforniaRiverside, P.O. Box 5900, Riverside, CA 92517. 